\title{
Value Chain Agribisnis Mangga Gedong Gincu (Mangifera Indica I) di Majalengka
}

D O I:10.18196/ agr.1216

\begin{abstract}
The objective of this research was to analyze the value chain and efficiency of gedong gincu mango agribusiness in Majalengka Regency. The data collection was conducted by interview techniques, using questionnaire. The samples of this study were: 88 farmers gedong gincu mango taken by using proportional random sampling, 28 sellers taken by snowball sampling, consisted of 15 local collectors, 3 big traders and 10 retailers. Value chain was analyzed using $\mathrm{R} / \mathrm{C}$ ratio. Marketing efficiency was analyzed by calculating the marketing margin, profit margin, farmer's share and marketing efficiency. The results showed that R/C ratio of farmers, small collectors, big collectors and retailers were $>1$. Highest profit level was achieved by farmers.
\end{abstract}

Based on marketing margins, farmer's share and marketing efficiency, all marketing channels were categorized as efficient.

Keywords: gedong gincu mango, value chain, marketing efficiency.

\section{INTISARI}

Tujuan penelitian ini adalah menganalisis rantai nilai (value chain) dan efisiensi pemasaran agribisnis mangga Gedong Gincu di Kabupaten Majalengka. Pengumpulan data dilakukan dengan teknik wawancara menggunakan kuesioner yang sudah disiapkan. Sampel yang digunakan dalam penelitian ini terdiri atas: 88 sampel petani yang ditentukan dengan proportional random sampling, 28 sampel pedagang yang ditentukan dengan snowball sampling yang terdiri atas pedagang pengumpul besar 3 orang, pedagang pengumpul kecil 15 orang dan pengecer 10 orang. Rantai nilai dianalisis dengan menggunakan rasio R/C. Efisiensi pemasaran dianalisis dengan menghitung margin pemasaran, marjin keuntungan, farmer's share dan efisiensi pemasaran. Hasil penelitian menunjukkan bahwa rasio R/C petani, pengumpul kecil, pengumpul besar dan pengecer $>1$. Tingkat keuntungan paling tinggi secara nominal diraih oleh petani. Ditinjau dari marjin pemasaran, keuntungan, farmers's share, efisensi pemasaran, semua saluran pemasaran dikategorikan efisien.

Kata kunci: rantai nilai, mangga gedong gincu, efisiensi pemasaran.

\section{PENDAHULUAN}

Mangga gedong gincu (Mangifera indica L) merupakan salah satu jenis mangga dari Indonesia yang memiliki kekhasan tersendiri. Mangga ini berperan sebagai sumber vitamin dan mineral, sumber pendapatan dan lapangan kerja serta salah satu penghasil devisa bagi negara. Kabupaten Majalengka merupakan salah satu sentra komoditi mangga gedong gincu di Jawa Barat. Berdasarkan Laporan dari Dinas Pertanian dan Perikanan Kabupaten Majalengka (2012), mangga gedong gincu di Kabupaten 
Majalengka memiliki luas tanam pada tahun 2011 seluas $3.210,42$ ha dan produktivitas sebesar 8 ton/ha. Data tersebut menunjukkan bahwa sentra mangga gedong gincu di Kabupaten Majalengka cukup luas, serta produktivitas per hektar cukup tinggi, hal tersebut mengindikasikan bahwa Kabupaten Majalengka sangat berpotensi untuk dikembangkan usaha agribisnis mangga gedong gincu.

Tingginya potensi Kabupaten Majalengka sebagai salah satu sentra mangga gedong gincu di Jawa Barat, ternyata di dalamnya masih menyisakan beberapa permasalahan. Permasalahan yang terjadi mulai dari proses produksi sampai pada proses pemasaran yang di dalamnya melibatkan berbagai pelaku maupun lembaga/ instansi terkait. Penanganan ketika panen, pengemasan, penyimpanan, pengangkutan yang dilakukan dengan sekedarnya, kurang diperhatikannya teknik budidaya yang baik dan benar untuk menghasilkan komoditi mangga yang bermutu sehingga mutu yang diperoleh sangat rendah. Bentuk buah yang masih belum seragam dan fluktuasi harga antara musim raya dan musim paceklik menyebabkan mangga gedong gincu tidak memiliki posisi penawaran harga yang tinggi. Dengan demikian, diperlukan adanya perbaikan rantai nilai mulai dari produsen sampai konsumen dengan melibatkan lembaga/instansi yang terkait dalam agribisnis mangga gedong gincu. Selain itu, perlu adanya alternatif saluran pemasaran yang efisien untuk meningkatkan harga jual dan keuntungan petani, karena tujuan efisiensi pemasaran adalah menciptakan kondisi yang saling menguntungkan bagi lembaga-lembaga yang terlibat dalam saluran pemasaran.

Menurut Irianto dan Widiyanti (2013), permasalahan yang sering muncul dalam sistem agribisnis hortikultura pada umumnya adalah permasalahan mulai dari tahap produksi hingga tahap pemasaran hasil hortikultura belum sepenuhnya memberikan insentif yang optimal kepada petani yang selama ini mengusahakannya. Bagian nilai tambah yang diterima petani (produsen) masih minimal bila dibandingkan dengan pelaku pada mata rantai yang lain. Oleh karena itu perlu dilakukan penelitian untuk memperbaiki kinerja rantai nilai tersebut.

Berdasarkan uraian tersebut, maka penelitian ini bertujuan untuk menganalisis rantai nilai (value chain) dan menganalisis efisiensi pemasaran mangga gedong gincu di Kabupaten Majalengka.

\section{METODE PENELITIAN}

Penelitian rantai nilai agribisnis manga gedong gincu (Mangifera indica L) di Kabupaten Majalengka menggunakan data primer dan sekunder. Data primer dikumpulkan melalui kuesioner petani, pedagang pengumpul kecil, pedagang pengumpul besar dan pedagang pengecer. Data sekunder diperoleh dari Badan Pusat Statistik Kabupaten Majalengka, Dinas Pertanian dan Perikanan Kabupaten Majalengka, Dinas Pertanian Provinsi Jawa Barat. Penelitian ini dilakukan di 3 Kecamatan, yaitu Kecamatan Kertajati, Kecamatan Panyingkiran dan Kecamatan Majalengka. Pertimbangan penentuan lokasi berdasar pada hasil produksi mangga gedong gincu tiga terbesar wilayah kecamatan di Kabupaten Majalengka (Tabel.1). Penelitian ini dilakukan pada Januari sampai dengan bulan Maret 2014.

TABEL I. LUAS TANAM, LUAS PANEN, PRODUKSI DAN PRODUKTIVITAS MANGGA GEDONG GINCU DI KABUPATEN MAJALENGKA TAHUN 20II

\begin{tabular}{|c|c|c|c|c|c|}
\hline No & Kecamatan & Luas Areal Tanam & Luas Panen & Produksi & Produktivitas \\
\hline & & --.---Ha --.-- & & ---Ton -- & ---Ton/Ha -- \\
\hline 1 & Majalengka & 586,56 & 411 & 3.452 & 8,40 \\
\hline 2 & Panyingkiran & 906,00 & 634 & 5.395 & 8,51 \\
\hline 3 & Kertajati & $1.199,04$ & 719 & 5.500 & 7,65 \\
\hline 4 & Ligung & 166,50 & 133 & 1.015 & 7,63 \\
\hline \multirow[t]{2}{*}{5} & Jatitujuh & 352,32 & 282 & 2.199 & 7,81 \\
\hline & Jumlah & $3.210,42$ & 2.179 & 17.561 & 40,00 \\
\hline
\end{tabular}

Sumber: Dinas Pertanian dan Perikanan Kabupaten Majalengka (2012)

Waktu penelitian mulai bulan Januari-Maret 2014. Sampel petani ditentukan dengan cara proportional random sampling sebagai entry point, kemudian dilakukan penelusuran dengan menggunakan bola salju (snowball sampling) untuk mendapatkan sampel pedagang hingga sampai ke konsumen, hal ini dilakukan untuk merunut alur aliran produk mulai dari hulu sampai hilir.

Berdasarkan teknik ini didapatkan sampel petani 88 orang, pedagang pengumpul kecil 15 orang, pedagang pengumpul besar 3 orang dan pedagang pengecer 10 orang. Analisis rantai nilai yang digunakan di petani, pedagang pengumpul kecil, pedagang pengumpul besar dan pedagang pengecer menggunakan perbandingan penerimaan dan biaya ( $\mathrm{R} / \mathrm{C}$ ratio) dan menggunakan tahapan-tahapan analisis rantai nilai, yaitu titik awal (entry point), pemetaan rantai nilai (value chain mapping), analisis struktur lembaga terkait (analysis of governance structure), faktor penting keberhasilan (critical success 
factor) dan perbaikan rantai nilai (upgrading value chain) (Kaplisky dan Morris, 2001).

\section{METODE ANALISIS}

\section{ANALISIS RANTAI NILAI}

Menurut Kaplinsky dan Morris (2001), tahapantahapan yang digunakan untuk analisis rantai nilai adalah sebagai berikut:

a. Titik awal

Titik awal yaitu menentukan di titik mana penelitian akan dimulai. Titik awal dalam penelitian analisis rantai nilai mangga gedong gincu ini adalah petani mangga gedong gincu kemudian dilakukan penelusuran dengan sistem bola salju untuk mendapatkan sampel pada titik berikutnya hingga sampai ke konsumen.

b. Pemetaan rantai nilai

Pemetaan rantai nilai ditentukan setelah teridentifikasi pelaku utama rantai nilai dan pelakupelaku lain yang diperoleh dengan merunut ke belakang (go backward) maupun ke depan (go forward), ditentukan pendapatan setiap pelaku yang diperoleh melalui hubungan input-output dan kemudian menghitung kelayakan usaha.

Menurut Hanafie (2010), metode pendekatan yang digunakan untuk perhitungan layak atau tidaknya usaha dapat dilakukan dengan menghitung Revenue/ Cost Ratio dengan rumus:

$\mathrm{R} / \mathrm{C}$ ratio $=$ Penerimaan Biaya Produksi

Kriteria yang digunakan:

Rasio R/C > 1, maka usahatani layak diusahakan Rasio R/C $<1$, maka usahatani tidak layak diusahakan

Rasio $\mathrm{R} / \mathrm{C}=1$, maka usahatani dikatakan impas, tidak memberikan keuntungan dan kerugian dalam analisis kelayakan dikatakan tidak layak.

c. Analisis lembaga terkait

Analisis lembaga terkait ditentukan setelah pelaku dan peta rantai nilai diketahui maka perlu diidentifikasi lembaga terkait mana saja yang dapat dilibatkan untuk perbaikan rantai nilai mangga gedong gincu.

d. Faktor penting keberhasilan
Orientasi keberhasilan suatu produk bukan ditentukan oleh kekuatan perusahaan untuk memasok sejumlah produknya namun ditentukan oleh kemampuan perusahaan (jaringan, teknologi, produksi dan sebagainya) untuk memenuhi kebutuhan pasar baik dalam kuantitas maupun kualitas yang sesuai, hal tersebut dikarenakan perkembangan sistem produksi saat ini cenderung bergeser dari pola tarikan pemasok (supplier pushed) ke arah dorongan pasar (market-pulled). Oleh karena itu, studi tentang rantai nilai sangat memperhatikan karakteristik pasar produk akhir disetiap rantai (Irianto dan Widayanti, 2013).

e. Perbaikan rantai nilai

Perbaikan rantai nilai dilakukan dengan mengoptimalkan tingkatan efisiensi mata rantai yang sudah ada dengan tetap mengedepankan asas berkeadilan bagi setiap pelaku dalam mata rantai pemasaran.

\section{ANALISIS EFISIENSI PEMASARAN}

Menurut Andayani (2007), penentuan tingkat efisiensi pemasaran dapat menggunakan beberapa variabel, yaitu margin keuntungan (profit margin), marjin pemasaran (marketing margin) dan bagian petani (farmers share).

a) Marjin Pemasaran

Marjin pemasaran $(\mathrm{Mp})$ adalah selisih harga produk di tingkat konsumen $(\mathrm{Pr})$ dengan harga di tingkat produsen (Pf) atau penjumlahan biaya pada tiap lembaga pemasaran (bi) dengan parameter keuntungan masing-masing (ki).

$\mathrm{Mp}=\mathrm{Pr}-\mathrm{Pf}$ atau $\mathrm{Mp}=$ "bi + "ki dimana:

$\mathrm{Mp}=$ Marjin pemasaran

$\operatorname{Pr} \quad=$ Harga di tingkat konsumen

Pf = Harga di tingkat produsen

bi = Biaya tata niaga ke-i

$\mathrm{ki}=$ keuntungan $\mathrm{ke}-\mathrm{i}$

Semakin besar marjin pemasaran maka makin tidak efisien dalam pemasaran tersebut.

b) Marjin Keuntungan

Menurut Andayani (2007), Keuntungan adalah selisih harga yang dibayarkan konsumen (rata-rata) dengan biaya pemasaran.

Keuntungan $=($ Harga jual $)-\{($ harga beli $)+($ biaya $)\}$

c) Bagian yang diterima petani

Menurut Soekartawi (2005), bagian harga yang 
GAMBAR I. RANTAI NILAI AGRIBISNIS MANGGA GEDONG GINCU DI KABUPATEN MAJALENGKA.

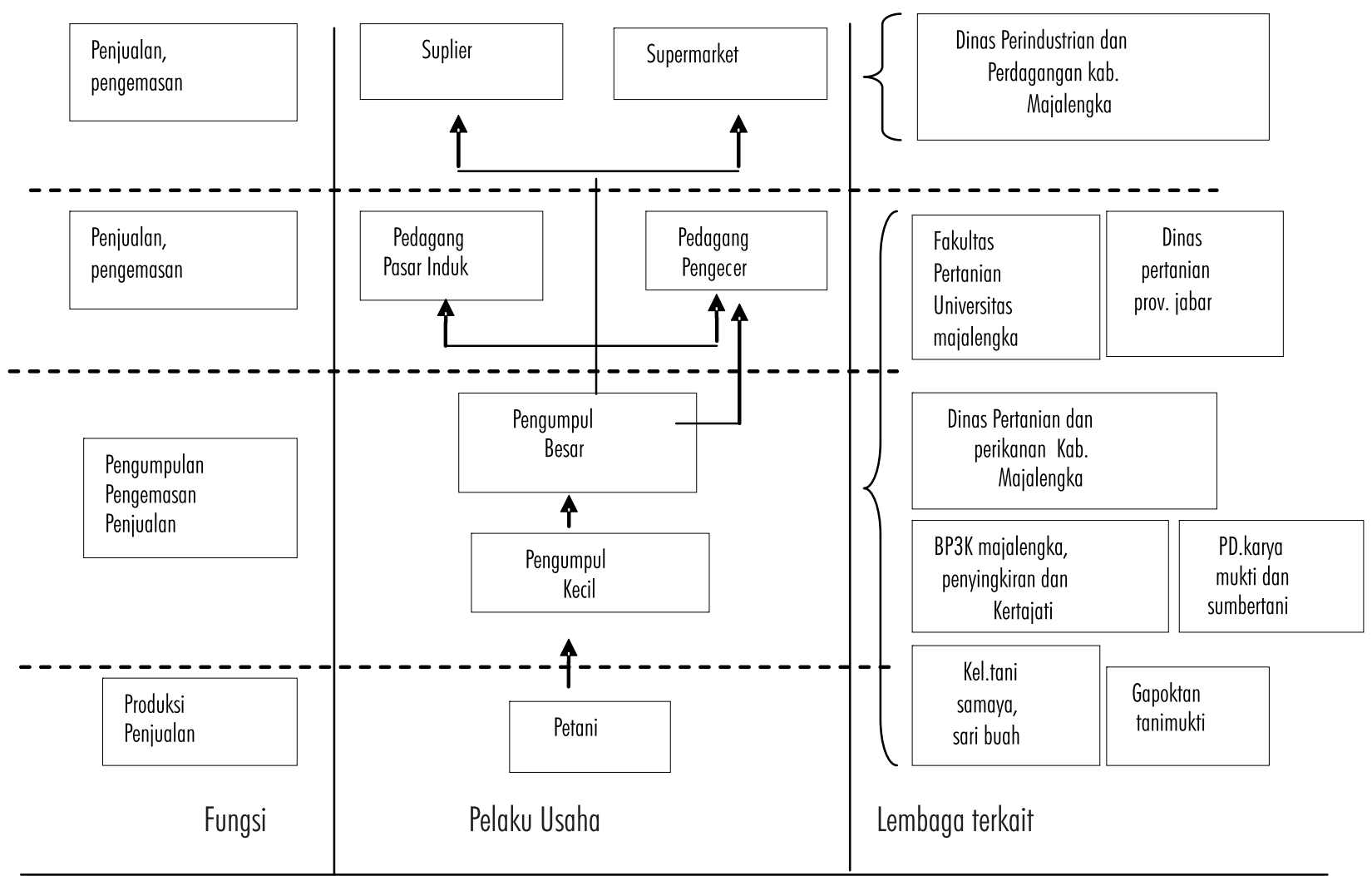

diterima Petani (SPf) adalah besarnya bagian yang diterima petani dari harga yang dibayar konsumen atas suatu produk yang dinyatakan dalam persen. Rumus farmer's share adalah sebagai berikut:

\section{$S P f=\frac{P f}{p r} \times 100 \%$}

dimana:

SPf $=$ Bagian harga di tingkat petani

$\operatorname{Pr} \quad=$ Harga di tingkat konsumen

Pf = Harga di tingkat petani

d) Efisiensi Pemasaran

Efisiensi pemasaran dapat dihitung dengan menggunakan rumus efisiensi pemasaran (Ep) (Downey dan Erickson, 1992) sebagai berikut:

$\mathrm{Ep}=$ Biaya Pemasaran

Nilai Produk yang Dipasarkan

Kaidah Keputusan:

1. $\quad E p>1$ berarti tidak efisien

2. $\mathrm{Ep}<1$ berarti efisien

\section{HASIL DAN PEMBAHASAN RANTAI NILAI MANGGA GEDONG GINCU}

Hasil Pemetaan Rantai Nilai

Hasil pemetaan rantai nilai mangga gedong gincu di Kabupaten Majalengka dapat dilihat pada Gambar 1. Pada diagram rantai nilai agribisnis mangga gedong gincu di Kabupaten Majalengka yang berfungsi sebagai produsen adalah petani. Pedagang pengumpul kecil dan pedagang pengumpul besar adalah lembaga pemasaran yang melakukan aktivitas pengumpulan, pengemasan dan penjualan. Pedagang pasar induk, pedagang pengecer, supplier dan supermarket melakukan fungsi penjualan dan pengemasan. Pada tiap-tiap fase rantai pemasaran terdapat peran lembaga terkait agribisnis mangga gedong gincu, diantaranya yaitu kelompok tani Sari Buah, kelompok tani Samaya, Gapoktan Tani Mukti, BP3K Kecamatan Majalengka, BP3K Kecamatan Panyingkiran, BP3K Kecamatan Kertajati, Perusahaan Pembibitan mangga PD Karyamukti, PD Sumbertani, Dinas Pertanian dan Perikanan Kabuapaten Majalengka, Dinas Pertanian Provinsi Jawa Barat, Disperindag Kabupaten Majalengka dan Fakultas Pertanian Universitas Majalengka. 
Berdasarkan hasil penelitian di lapangan, pola saluran pemasaran mangga gedong gincu di Kabupaten Majalengka terdapat 9 pola saluran pemasaran yaitu:

1. Pola Saluran 1: Petani-Pengumpul kecil-Pengumpul besar-Pengecer lokal-Konsumen.

2. Pola Saluran 2: Petani-Pengumpul kecil-Pengumpul besar-Pedagang di pasar induk-Pengecer luar daerahKonsumen.

3. Pola Saluran 3: Petani-Pengumpul kecil-Pengumpul besar-Suplier-Supermarket -Konsumen.

4. Pola Saluran 4: Petani-Pengumpul kecil-Pengumpul besar-Suplier-Eksportir-Konsumen luar negeri.

5. Pola Saluran 5: Petani-Pengumpul kecil-Pengumpul besar-Supermarket-Konsumen.

6. Pola Saluran 6: Petani-Pengumpul besar-Pengecer lokalKonsumen.

7. Pola Saluran 7: Petani-Pengumpul besar-Pedagang di Pasar induk-Pengecer luar daerah-Konsumen.

8. Pola Saluran 8: Petani-Pengumpul besar-SuplierSupermarket-Konsumen.

9. Pola Saluran 9: Petani-Pengumpul besar- SupermarketKonsumen.

Pola saluran pemasaran yang dianalisis adalah pola saluran pemasaran yang mulai dari hulu sampai hilir pelakunya ada di Kabupaten Majalengka, pola saluran pemasaran tersebut yaitu pola saluran pemasaran 1 dan pola saluran pemasaran 6 .

Menurut Anugrah (2009), penentuan harga mangga biasanya ditentukan oleh pedagang pengumpul karena adanya ikatan diantara keduanya, keterikatan tersebut sebagian besar karena adanya ikatan modal berupa sarana produksi sehingga secara tidak langsung petani merupakan alat pengikat bagi proses kegiatan pemasaran. Para petani biasanya memiliki pembeli langganan, sehingga tidak setiap pedagang pengumpul bisa bebas untuk mengambil alih petani yang akan menjual mangga bila tidka dikenal sebelumnya, sekalipun harga penawaran tinggi.

Rantai nilai dari petani responden menunjukkan bahwa $100 \%$ responden petani dalam berusahatani mangga gedong gincu memperoleh keuntungan dan usahatani layak untuk diteruskan, hal tersebut dikarenakan penerimaan petani mangga gedong gincu per ha per tahun sebesar Rp 161.430.989 dan total biaya sebesar Rp 54.573.132 (Tabel 1) sehingga nilai R/C 2,96 (rasio $\mathrm{R} / \mathrm{C}>1$ ), maka usahatani yang dilakukan petani menguntungkan dan layak untuk diusahakan. Hasil penelitian ini sesuai dengan hasil kajian kelayakan usahatani mangga yang dilakukan oleh Supriatna (2007), dimana nilai R/C petani sebesar 4,64 sehingga usahatani ini menguntungkan dan layak untuk diusahakan.

TABEL I. ANALISA BIAYA PRODUKSI DAN PENDAPATAN PETANI MANGGA GEDONG GINCU PER HEKTAR PER TAHUN DI KABUPATEN MAJALENGKA

\begin{tabular}{lll}
\hline Keterangan & Jumlah (Rp) & Total Pengeluaran (\%) \\
\hline FAKTOR PRODUKSI & 27.075 .4189 & 49,61 \\
Bibit & 48.364 & \\
Pupuk & 25.328 .747 & 46,41 \\
Pestisida & 1.698 .308 & 3,11 \\
TENAGA KERJA & 14.897 .904 & 27,31 \\
Rehab. Tanaman & 241.319 & \\
Penyiangan & 1.808 .352 & \\
Pemupukan & 2.492 .308 & \\
Pengendalian HPT & 2.764 .396 & \\
Pemangkasan & 660.220 & \\
Panen dan pascapanen & 5.019 .780 & \\
Pengangkutan & 1.911 .530 & \\
(Biaya Variabel) & 41.973 .323 & \\
SEWA LAHAN & 10.989 .011 & \\
PAJAK & 68.597 & \\
PENY. ALAT PERTANIAN & 1.169 .455 & \\
BUNGA BANK & 372.747 & \\
(Biaya Tetap) & 12.599 .810 & 23,09 \\
Total Biaya & 54.573 .132 & \\
Total Penerimaan & 161.430 .989 & \\
Pendapatan & 106.857 .857 & \\
R/C & 2,96 & \\
\hline & & \\
\hline
\end{tabular}

Pedagang pengumpul kecil, pedagang pengumpul besar dan pedagang pengecer lokal (100\% responden) menunjukkan nilai $\mathrm{R} / \mathrm{C}>1$. Nilai $\mathrm{R} / \mathrm{C}$ pedagang pengumpul kecil pada pemasaran mangga gedong gincu kelas A/B sebesar 1,11 dan nilai R/C mangga gedong gincu kelas $\mathrm{C}$ sebesar 1,25 (Tabel 2). Masing-masing nilai $\mathrm{R} / \mathrm{C}>1$, artinya usaha agribisnis mangga gedong gincu kelas $\mathrm{A} / \mathrm{B}$ dan $\mathrm{C}$ yang dilakukan pedagang pengumpul kecil menguntungkan dan layak untuk diusahakan. Pedagang pengumpul kecil merupakan orang kepercayaan pedagang pengumpul besar. Satu pedagang pengumpul 
besar biasanya memiliki $10-15$ pedagang pengumpul kecil yang tersebar sampai ke luar kecamatan. Pedagang pengumpul kecil biasanya mendapatakan modal dari pengumpul besar untuk kebutuhan operasi. Pada saat kondisi produk mangga gedong gincu langka maka pedagang pengumpul kecil akan mendatangi kebunkebun petani mangga untuk melihat apakah sudah siap panen atau belum dan tidak jarang pedagang pengumpul kecil melakukan panen sendiri.

TABEL 2. ANALISA BIAYA DAN PENERIMAAN PADA PEDAGANG PENGUMPUL KECIL

\begin{tabular}{|c|c|c|c|c|}
\hline \multirow[t]{2}{*}{ Uraian } & \multicolumn{2}{|c|}{$\begin{array}{l}\text { Mangga kelas } A / B \\
(\mathrm{Rp} / \mathrm{Kg})\end{array}$} & \multicolumn{2}{|c|}{$\begin{array}{l}\text { Mangga kelas C } \\
(\mathrm{Rp} / \mathrm{Kg})\end{array}$} \\
\hline & Pola 1 & Pola 6 & Pola 1 & Pola 6 \\
\hline Pembelian & $15.000,00$ & - & $5.500,00$ & - \\
\hline Transportasi & 171,96 & & 246,81 & \\
\hline Retribusi & 3,64 & & 3,42 & \\
\hline Penimbangan & 6,42 & & 10,02 & \\
\hline Kemasan & 100,00 & & 116,44 & \\
\hline $\begin{array}{l}\text { Tenaga Kerja (Sortasi, } \\
\text { pengepakan dan Penjualan) }\end{array}$ & 307,23 & & 411,53 & \\
\hline Peny. Alat dan Bangunan & 0,40 & & 0,50 & \\
\hline Bunga Bank & 32,20 & & 26,39 & \\
\hline Resiko Kehilangan Hasil & 126,39 & & 63,20 & \\
\hline Total Biaya & $15.748,24$ & & $6.378,30$ & \\
\hline Penerimaan & $17.500,00$ & & $8.000,00$ & \\
\hline Keuntungan & $1.751,76$ & & $1.621,70$ & \\
\hline$R / C$ & 1,11 & & 1,25 & \\
\hline
\end{tabular}

Penerimaan pedagang pengumpul besar sebesar Rp 20.000 per $\mathrm{kg}$, biaya yang dikeluarkan untuk mendapatkan $1 \mathrm{~kg}$ mangga gedong gincu sebesar Rp 18.594,92 sehingga nilai $\mathrm{R} / \mathrm{C}$ sebesar 1,08 (pola saluran pemasaran 1 kelas $\mathrm{A} / \mathrm{B})$, penerimaan pedagang pengumpul besar pada pola saluran pemaran 6 sebesar Rp 18.000 per kg, biaya yang dikeluarkan sebesar Rp $15.833,47$ per kg sehingga nilai R/C sebesar 1,14. Penerimaan pedagang pengumpul besar (pola saluran pemasaran 6) lebih besar dari pada pola saluran pemarasan 1 , hal ini dikarenakan rantai pemasaran tidak terlalu panjang. Penerimaan pedagang pengumpul besar pada pola saluran 1 kelas C sebesar Rp 11.000,00 per kg, biaya yang dikeluarkan sebesar Rp 9.018,79 per kg maka nilai $\mathrm{R} / \mathrm{C}$ rationya sebesar 1,21. Pada pola saluran 6 kelas $\mathrm{C}$, pedagang pengumpul meperoleh penerimaan sebesar Rp 9.000,00 per kg, biaya yang dikeluarkan Rp 7.316,60 per $\mathrm{kg}$, maka nilai R/C sebesar 1,23. Nilai R/C pada pola 1 dan pola $6>1$, maka usaha agribisnis mangga gedong gincu grade $\mathrm{C}$ menguntungkan dan layak untuk diusahakan (Tabel 3).

Tabel 4 menunjukkan bahwa pedagang pengecer mangga gedong gincu (kelas A/B dan kelas C) memiliki nilai $\mathrm{R} / \mathrm{C}$ di setiap saluran pemasaran $>1$, baik pada pola saluran 1 maupun pola saluran 6 , sehingga usaha agribisnis yang dilakukan menguntungkan dan layak untuk diusahakan.

\section{PERAN KELEMBAGAAN TERKAIT}

Menurut Mangkuprawira (1996), agribisnis adalah suatu kesatuan sistem usaha yang antar subsistemnya (penyediaan faktor-faktor produksi, budidaya/ produksi, pengolahan/agroindustri, dan distribusi pemasaran) saling terkait dan keterkaitan tersebut dijalin oleh kelembagaan. Petani mangga gedong gincu di Majalengka sulit disatukan dalam satu kelembagaan, karena pada umumnya belum menyadari pentingnya berkelompok, meskipun tidak dipungkiri sudah ada kelompok mangga gedong gincu yang sudah melakukan kerja sama dengan beberapa perusahaan besar seperti kelompok tani mangga "Samaya" (Kecamatan Panyingkiran) yang bermitra dengan PT Alindo dan Kelompok tani mangga "Saribuah" (Kecamatan Majalengka) yang sudah bermitra dengan PT Alamanda, PT Entraco dan PT Mulya Raya. Berdasarkan hasil penelitian di lapangan, pemerintah khususnya dinas pertanian sudah melakukan pembinaan dan pelatihan melalui program SLPHT pada tanaman hortikultura dan program panen di luar musim, akan tetapi untuk kendala harga pemerintah belum memilki kekuatan. Harga dan penentu kualitas pada umumnya dikendalikan oleh para pedagang yang biasanya memiliki informasi lebih cepat, sementara petani hanya menerima saja harga dan kuaitas yang dikehendaki pedagang.

\section{FAKTOR PENTING KEBERHASILAN}

Berdasarkan hasil penelitian di lapangan, semua pelaku usaha agribisnis mangga gedong gincu sepakat bahwa kunci sukses utama dalam bisnis mangga gedong gincu adalah kualitas produk yang dihasilkan dari mata rantai yang mereka geluti. Kualitas produk mangga gedong gincu di Kabupaten Majalengka dapat dibedakan kedalam 3 kelas, yaitu kelas A (300-350 gram), kelas B (250-<300 gram) dan kelas C (200-<250 gram). Pasar terbagi dalam beberapa segmen, setiap pasar mempunyai karakteristik yang berbeda-beda. Karakteristik pasar 
TABEL 3. ANALISA BIAYA DAN PENERIMAaN PADA PEDAGANG PENGUMPUL BESAR PADA POLA SALURAN PEMASARAN I DAN 6 KELAS A/B DAN KELAS C

\begin{tabular}{|c|c|c|c|c|}
\hline \multirow[t]{2}{*}{ Uraian } & \multicolumn{2}{|c|}{$\begin{array}{l}\text { Mangga kelas } \\
\mathrm{A} / \mathrm{B}(\mathrm{Rp} / \mathrm{Kg})\end{array}$} & \multicolumn{2}{|c|}{$\begin{array}{l}\text { Mangga kelas C } \\
(\mathrm{Rp} / \mathrm{Kg})\end{array}$} \\
\hline & Saluran 1 & Pola 6 & Pola 1 & Pola 6 \\
\hline Pembelian & $17.500,00$ & $15.000,00$ & $8.000,00$ & $6.500,00$ \\
\hline Transportasi & 53,33 & 35,12 & 53,33 & 35,12 \\
\hline Retribusi & 1,00 & 0,49 & 1,00 & 0,49 \\
\hline Penimbangan & 5,00 & 2,45 & 5,00 & 2,45 \\
\hline Kemasan & 400,00 & 400,00 & 400,00 & 400,00 \\
\hline $\begin{array}{l}\text { Tenaga Keria } \\
\text { (Sortasi, } \\
\text { pengepakan dan } \\
\text { Penjualan) }\end{array}$ & 310,00 & 109,11 & 310,00 & 109,11 \\
\hline $\begin{array}{l}\text { Peny. Alat dan } \\
\text { Bangunan }\end{array}$ & 27,67 & 13,78 & 27,67 & 13,78 \\
\hline Bunga Bank & 166,67 & 103,77 & 166,67 & 103,77 \\
\hline $\begin{array}{l}\text { Resiko Kehilangan } \\
\text { Hasil }\end{array}$ & 131,25 & 168,75 & 118,13 & 151,88 \\
\hline Total Biaya & $18.594,92$ & $15.833,47$ & $9.018,79$ & $7.316,60$ \\
\hline Penerimaan & $20.000,00$ & $18.000,00$ & $11.000,00$ & $9.000,00$ \\
\hline Keuntungan & $1.405,08$ & $2.166,53$ & $1.918,21$ & $2.166,53$ \\
\hline$R / C$ & 1,08 & 1,14 & 1,21 & 1,23 \\
\hline
\end{tabular}

TABEL 4. ANALISA BIAYA DAN PENERIMAAN PEDAGANG PENGECER LOKAL

\begin{tabular}{lllll}
\hline Uraian & $\begin{array}{l}\text { Mangga kelas A/B } \\
(\mathrm{Rp} / \mathrm{Kg}) \\
\text { Pola 1 }\end{array}$ & Pola 6 & $\begin{array}{l}\text { Mangga kelas C } \\
(\mathrm{Rp} / \mathrm{Kg}) \\
\text { Pola 1 }\end{array}$ & Pola 6 \\
\hline Pembelian & $20.000,00$ & $18.000,00$ & $11.000,00$ & $9.000,00$ \\
Transportasi & 528,13 & 379,17 & 270,83 & 268,90 \\
Retribusi & - & 15,60 & 12,50 & 9,70 \\
Kemasan & 187,75 & 200,00 & 200,00 & 200,00 \\
Sortasi & 731,25 & 758,33 & 270,83 & 309,52 \\
Peniualan & 731,25 & 758,33 & 189,58 & 309,52 \\
Resiko & & & & \\
Kehilangan & $1.000,00$ & 900,00 & 550,00 & 450,00 \\
Hasil & & & & \\
Total Biaya & $23.178,13$ & $21.010,83$ & $12.493,75$ & $10.547,65$ \\
Penerimaan & $25.000,00$ & $23.000,00$ & $15.000,000$ & $13.000,00$ \\
Keuntungan & $1.821,88$ & $1.989,17$ & $2.506,25$ & $2.45,35$ \\
R/C Ratio & 1,08 & 1,09 & 1,20 & 1,23 \\
\hline
\end{tabular}


mencirikan faktor penting keberhasilan. Pelaku usaha agribisnis mangga gedong gincu di Kabupaten Majalengka banyak yang bermain di banyak segmen, tetapi dengan tetap mempertimbangkan jumlah konsumen pada segmen tersebut, tingkat kualitas produk yang diharapkan dan level harga yang sesuai. Mangga gedong gincu grade A/B dengan harga kisaran $\mathrm{Rp}$ 23.00025.000 biasanya dikirim ke pasar luar Kabupaten Majaelngka, dikirim ke pedagang pasar induk, supplier, supermarket bahkan sampai untuk keperluan ekspor yang memerlukan kualitas produk, meskipun mangga gedong gincu kelas A/B tetap di jual juga di pengecer lokal tetapi jumlahnya tidak sebanyak yang dikirimkan ke luar Majalengka. Mangga gedong gincu kelas $\mathrm{C}$ dengan kisaran harga Rp 13.000-15.000 biasanya di jual banyak di pengecer lokal di Kabupaten Majalengka.

\section{PERBAIKAN RANTAI NILAI}

Peran dari kelembagaan sangat penting dalam perbaikan rantai nilai agribisnis mangga gedong gincu dan dalam peningkatan kemampuan daya saing usaha mangga gedong gincu di Kabupaten Majalengka. Kelembagaan memiliki peran untuk mengakomodasi kebutuhan para pelaku usaha agribisnis mangga gedong gincu, utamanya agar kualitas produk yang dihasilkan dapat sesuai dengan standar, mengurangi persaingan yang tidak sehat diantara pelaku usaha, membina para pelaku penebas/pengijon agar bisa berusaha dengan baik dan benar dan membantu dalam perluasan pasar bersama di pasar yang sekarang telah ditembus maupun membuka alternatif pasar baru. Pada saat penelitian, sebenarnya telah ada asosiasi petani mangga gedong gincu, namun demikian kelembagaan yang berupa asosiasi tersebut dirasa belum secara optimal dalam memfasilitasi kebutuhan para pelaku usaha.

Menurut Irianto dan Widiyanti (2013), perbaikan rantai nilai dapat dilakukan selain dengan mengoptimalkan peran lembaga, juga dapat dilakukan dengan mengoptimalkan tingkat efisiensi mata rantai yang ada dengan tetap mengedepankan asas berkeadilan bagi semua pelaku dalam mata rantai pemasaran agribisnis mangga gedong gincu tersebut. Dengan demikian efisiensi pemasaran agribisnis mangga gedong gincu di Kabupaten Majalengka adalah sangat penting dalam rangka memperbaiki rantai nilai mangga gedong gincu yang ada.

\section{EFISIENSI PEMASARAN}

\section{MARJIN PEMASARAN, MARJIN KEUNTUNGAN, BAGIAN PETANI DAN ANALISIS EFISIENSI PEMASARAN}

Dalam pemasaran mangga gedong gincu, harga produk mangga gedong gincu yang dihasilkan petani dibedakan menjadi 2 kategori yaitu kelas A/B dan kelas C. Perbedaan kelas mangga gedong gincu juga mempengaruhi harga jual. Menurut Roesmawati (2010), marjin pemasaran yaitu selisih harga jual dan harga beli dan merupakan salah satu indikator yang digunakan untuk mengukur tingkat efisiensi suatu sistem pemasaran. Marjin pemasaran terdiri atas biaya pemasaran dan keuntungan lembaga pemasaran. Berdasarkan Tabel 4 diketahui total marjin pemasaran pada pola saluran 1 ( Rp 10.000 per $\mathrm{kg}$ ) dan total marjin pemasaran pada pola saluran 6 ( Rp 8.000 per $\mathrm{kg}$ ). Marjin pemasaran pada pola saluran 1 lebih besar dari pada pola saluran 6. Menurut Hanafie (2010), Tinggi rendahnya marjin pemasaran dipakai untuk mengukur efisiensi sistem pemasaran. Semakin tinggi marjin pemasaran maka makin tidak efisien sistem pemasaran tersebut. Marjin pemasaran semakin tinggi akibat bagian harga petani menjadi kecil. Hal ini sangat tidak menggairahkan produsen untuk berproduksi. Selain itu, marjin pemasaran akan semakin bertambah jika semakin banyak lembaga pemasaran yang terlibat, dengan demikian semakin panjang saluran pemasarannya maka semakin besar marjinnya, sehinggga menyebabkan harga di tingkat konsumen akan lebih mahal.

Menurut Andayani (2007), Keuntungan pemasaran merupakan selisih harga yang dipasarkan ke produsen dengan harga yang diberikan ke konsumen dikurangi dengan biaya-biaya pemasaran.

Berdasarkan Tabel 4 diketahui bahwa keuntungan lembaga pemasaran yang terkecil adalah pedagang pengumpul besar pada pola saluran 1 yaitu sebesar Rp1.405,08/kg dan keuntungan tertinggi adalah pedagang pengecer yaitu sebesar Rp1.989,17/kg (pola saluran 6). Hal ini disebabkan saluran pemasaran yang yang dilalui cukup pendek sehingga dapat menekan biaya pemasaran dan masrjin pemasaran.

Bagain petani merupakan persentase perbadingan antara harga di tingkat petani dan harga di tingkat konsumen akhir. Nilai bagian petani pada pola saluran 1 $(60,00 \%)$ dan pada pola saluran $6(65,22 \%)$. Nilai bagian petani dari kedua pola saluran pemasaran cukup tinggi. 
TABEL 4. HASIL ANALISIS MARJIN PEMASARAN, KEUNTUNGAN, BAGIAN PETANI DAN EFISIENSI PEMASARAN MANGGA GEDONG GINCU KELAS A/B

\begin{tabular}{|c|c|c|c|c|}
\hline \multirow{2}{*}{ Keterangan } & \multicolumn{2}{|c|}{ Pola Saluran 1} & \multicolumn{2}{|c|}{ Pola Saluran 6} \\
\hline & Jumlah & Bagian petani & Jumlah & Bagian petani \\
\hline & $\mathrm{Rp} / \mathrm{Kg}$ & $\%$ & $\mathrm{Rp} / \mathrm{Kg}$ & $\%$ \\
\hline \multicolumn{5}{|l|}{ Petani } \\
\hline Biaya Produksi & $4.661,30$ & 60,00 & $4.661,30$ & 65,22 \\
\hline Harga Jual & $15.000,00$ & & $15.000,00$ & \\
\hline Keuntungan & $10.338,70$ & & $10.338,70$ & \\
\hline \multicolumn{5}{|c|}{ Pedagang Pengumpul Kecil } \\
\hline Harga Beli & $15.000,00$ & & - & \\
\hline Biaya pemasaran & 748,24 & & - & \\
\hline Harga Jual & $17.500,00$ & & - & \\
\hline Keuntungan & $1.751,76$ & & - & \\
\hline Marjin Pemasaran & $2.500,00$ & & - & \\
\hline \multicolumn{5}{|c|}{ Pedagang Pengumpul Besar } \\
\hline Harga Beli & $17.500,00$ & & $15.000,00$ & \\
\hline Biaya pemasaran & $1.094,92$ & & $1.094,92$ & . \\
\hline Harga Jual & $20.000,00$ & & $18.000,00$ & \\
\hline Keuntungan & $1.405,08$ & & $1.905,08$ & \\
\hline Mariin Pemasaran & $2.500,00$ & & $3.000,00$ & \\
\hline \multicolumn{5}{|l|}{ Pedagang Pengecer } \\
\hline Harga beli & $20.000,00$ & & $18.000,00$ & \\
\hline Biaya pemasaran & $3.178,13$ & & $3.010,83$ & \\
\hline Harga Jual & $25.000,00$ & & $23.000,00$ & \\
\hline Keuntungan & $1.821,87$ & & $1.989,17$ & \\
\hline Mariin Pemasaran & $5.000,00$ & & $5.000,00$ & \\
\hline Harga Beli Konsumen & $25.000,00$ & & $23.000,00$ & \\
\hline Total Biaya Pemasaran & $5.021,29$ & & $4.105,75$ & \\
\hline Total Keuntungan & $15.317,51$ & & $14.233,05$ & \\
\hline Total Mariin Pemasaran & $10.000,00$ & & $8.000,00$ & \\
\hline Efisiensi & 0,20 & & 0,18 & \\
\hline
\end{tabular}

Menurut Roesmawaty (2011), semakin tinggi tingkat persentase bagain petani maka semakin efisien kegiatan pemasaran yang dilakukan dan sebaliknya semakin rendah tingkat persentase bagian petani maka akan semakin rendah pula tingkat efisiensi dalam kegiatan pemasaran tersebut. Berdasarkan Tabel 4 nilai bagian petani pada saluran $6(65,22 \%)$ lebih tinggi dari pada pola saluran $1(60,00 \%)$, sehingga jika mengacu pada Roesmawati (2011) maka pola saluran 6 lebih efisien dibandingkan pola saluran 1 . 
TABEL 5. haSIL ANALISIS MARJIN PEMASARAN, KEUNTUNGAN, BAGIAN PETANI DAN EFISIENSI PEMASARAN MANGGA GEDONG GINCU KELAS C

\begin{tabular}{|c|c|c|c|c|}
\hline \multirow[b]{2}{*}{ Keterangan } & \multicolumn{2}{|l|}{ Pola Saluran 1} & \multicolumn{2}{|c|}{ Pola Saluran 6} \\
\hline & Jumlah & Bagian petani & Jumlah & $\begin{array}{l}\text { Bagian } \\
\text { petani }\end{array}$ \\
\hline & $-\mathrm{Rp} / \mathrm{Kg}-$ & $-\%$ & $-\mathrm{Rp} / \mathrm{Kg}-$ & $-\%-$ \\
\hline \multicolumn{5}{|l|}{ Petani } \\
\hline Biaya Produksi & $4.661,30$ & 36,67 & $4.661,30$ & 42,31 \\
\hline Harga Jual & $5.500,00$ & & $5.500,00$ & \\
\hline Keuntungan & 838,70 & & 838,80 & \\
\hline \multicolumn{5}{|c|}{ Pedagang Pengumpul Kecil } \\
\hline Harga Beli & $5.500,00$ & & - & \\
\hline Biaya pemasaran & 878,80 & & - & \\
\hline Harga Jual & $8.000,00$ & & - & \\
\hline Keuntungan & $1.621,70$ & & - & \\
\hline Marijin Pemasaran & $2.500,00$ & & - & \\
\hline \multicolumn{5}{|c|}{ Pedagang Pengumpul Besar } \\
\hline Harga Beli & $8.000,00$ & & $6.500,00$ & \\
\hline Biaya pemasaran & $1,080,79$ & & 816,60 & \\
\hline Harga Jual & $11.000,00$ & & $9.000,00$ & \\
\hline Keuntungan & $1.918,21$ & & $1.683,40$ & \\
\hline Marjin Pemasaran & $3.000,00$ & & $2.500,00$ & \\
\hline \multicolumn{5}{|l|}{ Pedagang Pengecer } \\
\hline Harga beli & $11.000,00$ & & $9.000,00$ & \\
\hline Biaya pemasaran & $1.493,75$ & & $1.547,65$ & \\
\hline Harga Jual & $15.000,00$ & & $13.000,00$ & \\
\hline Keuntungan & $2.506,25$ & & $2.452,35$ & \\
\hline Marjin Pemasaran & $4.000,00$ & & $4.000,00$ & \\
\hline Harga Beli Konsumen & $15.000,00$ & & $13.000,00$ & \\
\hline Total Biaya Pemasaran & $3.453,84$ & & $2.364,25$ & \\
\hline Total Keuntungan & $6.884,96$ & & $4.974,55$ & \\
\hline Total Mariin & $9.500,00$ & & $6.500,00$ & \\
\hline Efisiensi & 0,23 & & 0,18 & \\
\hline
\end{tabular}

Nilai efisiensi pemasaran pada saluran 1 sebesar 0,20 dan pada saluran 6 sebesar 0,18. Menurut Downey dan Erickson (1992), suatu saluran pemasaran akan dinilai efisien jika nilai efisiensi $<1$ dan dinilai tidak efisien jika nilai efisiensi $>1$, Jika melihat nilai efisiensi pada kedua pola saluran mangga gedong gincu kelas $\mathrm{A} / \mathrm{B}$ tersebut, maka kedua saluran pemasaran tersebut dikategorikan efisien.

Tabel 5 menunjukkan analisis marjin pemasaran, keuntungan, bagian petani dan efisiensi pemasaran mangga gedong gincu kelas $\mathrm{C}$. Total marjin pemasaran pada pola salursan 1 sebesar Rp 9.500,00/kg sedangkan pada pola saluran 6 sebesar Rp 6.500,00/kg. Total marjin pemasaran pada pola saluran 1 lebih besar dari pada pola saluran pemasaran 6 , hal tersebut dikarenakan pada pola saluran 1 lebih banyak lembaga pemasaran yang terlibat. Total keuntungan pada pola saluran pemasaran 1 sebesar Rp 6.884,96 per kg, sedangakan keuntungan pada pola saluran pemasaran 6 lebih rendah yaitu sebesar $\mathrm{Rp}$ $4.974,55$ per kg. Perbedaan keuntungan disebabkan karena perbedaan biaya yang dikeluarkan dan perbedaan marjin pemasaran. Nilai bagian petani pada pola saluran 
6 lebih besar dari pada pola saluran 1, nilai bagian petani pola saluran 1 sebesar 36,67 sedangkan pada pola saluran 6 sebesar 42,31. Mengacu pada pendapat (Roesmawati, 2011), semakin tinggi tingkat persentase bagian petani maka semakin efisien kegiatan pemasaran yang dilakukan dan sebaliknya. Berdasarkan tabel 5 nilai bagian petani pada pola saluran 6 lebih besar dari pada nilai bagian petani pada pola saluran 1 sehingga pola saluran 6 lebih efisien. Nilai efisiensi saluran 1 sebesar 0,23 dan saluran 6 sebesar 0,18 nilai keduanya $<1$ sehingga kedua saluran tersebut dikategorikan efisien.

\section{KESIMPULAN}

Rantai nilai dari petani maupun pedagang menunjukkan bahwa usaha yang mereka lakukan menguntungkan dan layak diusahakan karena nilai $\mathrm{R} / \mathrm{C}$ ratio masing-masing pelaku $>1$, Pelaku dalam rantai nilai mangga gedong gincu di Kabupaten Majalengka terdiri atas 9 pelaku dan membentuk 9 pola saluran pemasaran. Pola saluran pemasaran yang ada di Majalengka mulai dari hulu sampai hilir hanya terdapat 2 pola, yaitu pola saluran pemasaran 1 dan pola saluran pemasaran 6 . Tingkat keuntungan secara nominal paling tinggi adalah petani. Ditinjau dari marjin pemasaran, marjin keuntungan, bagian petani dan efisiensi pemasaran menyatakan bahwa saluran pemasaran 6 relatif lebih efisien disbandingkan saluran pemasaran 1 .

Perlunya pembinaan dan pelatihan bagi para pelaku agribisnis mangga gedong gincu baik oleh pemerintah maupun lembaga terkait lainnya, dalam rangka peningkatan dan perbaikan mutu dari kualitas mangga gedong gincu melalui teknik budidaya yang baik, agar dapat memenuhi standar kualitas yang diinginkan oleh konsumen, terutama penampilan secara fisik mangga gedong gincu sampai ukuran yang memenuhi standar kualitas ekspor. Pemerintah dan dinas terkait daerah setempat perlu memfasilitasi mengenai kemudahan untuk akses informasi dan penyediaan modal yang bisa diperoleh oleh petani dan para pelaku agribisnis mangga gedong gincu, agar bisa membuka alternatif saluran pemasaran baru terutama untuk tujuan ekspor.

\section{DAFTAR PUSTAKA}

Andayani, W. 2007. Analisis efisiensi pemasaran kacang mete (Chasew Nuts) di Kabupaten Wonogiri. Jurnal Akta Agrois. 10 (01): 57-58.

Anugrah, I .S. 2009. Mendudukan komoditas mangga sebagai unggulan daerah dalam suatu kebijakan sistem agribisnis-upaya menyatukan dukungan kelembagaan bagi eksistensi petani. Analisis Kebijakan Pertanian.7 (02):189-211.

Dinas Pertanian dan Perikanan Kabupaten Majalengka. 2012. Buku Laporan Tahunan. Dinas Pertanian dan Perikanan Kabupaten Majalengka.

Downey,W.D. dan S.P. Erickson. 1992. Manajemen Agribisnis. Erlangga. Jakarta.

Hanafie, R. 2010. Pengantar Ekonomi Pertanian. ANDI Yogyakarta. Yogyakarta.

Irianto, H. dan E. Widiyanti. 2013. Analisis value chain dan efisiensi pemasaran agribisnis jamur kuping di Kabupaten Karanganyar. Jurnal Sosial Ekonomi Pertanian dan Agribisnis (SEPA). 9(2): 260-263.

Kaplinsky, R. and M. Morries. 2001. A Handbook for Value Chain Research, <http://www.ids.ac.uk/ids/global/ valchn.html\#manuals> (diakses 02 Juni 2013.

Mangkuprawira, S. 1996. Hubungan kelembagaan dalam agribisnis. Agrimedia. 2(2):13.

Roesmawaty, H. 2011. Analisa efisiensi pemasaran pisang di Kecamatan Lengkiti Kabupaten Ogan Komering Ulu. Jurnal Agribisnis. 3(5):1-9.

Supriatna, A. 2005. Kajian Kelayakan Usahatani dan Marjin Pemasaran Tataniaga Mangga (mangifera indica) (Studi Kasus di Kabupaten Majalengka Jawa Barat,2005). Laporan Akhir Penelitian. Balai Besar Pengkajian dan Pengembangan Teknologi Pertanian. Bogor, Jawa Barat.

Soekartawi. 2005. Prinsip Dasar-Hasil Pertanian Teori dan Aplikasinya. PT Grafindo Persada. Jakarta. 